The object of the survey is to map the boundaries of the distinctive soil patterns, which are known to exist over large areas, and which are determined by the underlying rocks, by climate, relief, and drainage. Within each soil pattern a small area will be surveyed in detail.

\title{
Petition of the Bakweri Land Committee, Cameroons under British Mandate
}

A pETrTIon dated 24 August 1946 was forwarded to the Governor of Nigeria with a request that it be presented to the Trusteeship Council of the United Nations. The petition formulated a demand on the part of the Bakweri Land Committee, which claims to represent ' the entire populace of the Bakweri people i.e. including the sub-tribes of Bota and Bimbia of the Victoria Division in the Cameroons under British Mandate', for the return of 580 square miles of land which were alienated by the German Government during their administration of the area, and sold or leased as plantations, or to missions, or retained as Crown lands. The Bakweri Land Committee states that there was no legal sale of the land to the German administration or any agreement concluded with the Bakweri people; they state also that the areas remaining to them are 'rocky barren upland slopes', or swamps and bogs, unfit for cultivation; that they have attempted cultivation on the mountain slopes without success, except in the case of the coco-yam, which has proved unsuitable for food, and that they therefore suffer from malnutrition; further, the cultivation of these mountain areas imposes too heavy a strain on the women, who 'by custom are the planters of our locally consumed food stuffs', and causes early breakdowns in health, infant mortality, and deterioration of the people.

The Bakweri Land Committee therefore asks that all land shall be returned to the Bakweri people, that its cultivation shall be regulated by the Native Authority who, in consultation with the Committee, shall apply any profits accruing for the benefit of the people. They also ask, as compensation for the exploitation of their land, for costs equal to the proceeds which have accrued from the plantations during the last five years.

The petition was duly forwarded to the Secretary-General of the United Nations. On 9 June 1948 certain observations by the United Kingdom Government on the petition were forwarded to the Secretary-General of the United Nations, in which it was pointed out that all lands had been declared native lands and had been placed under the control of the Governor of Nigeria to be administered for the use and common benefit of the natives; that the Nigerian Government had repurchased $14,85 \mathrm{I}$ acres of plantation land for the benefit of the natives, and that the Cameroons Development Corporation had been set up to administer and develop the plantations until such time as the Bakweri people wete competent to manage them without assistance; moreover, a senior Administrative Officer had been appointed to make a survey of land in the Victoria Division in order to ensure that the inhabitants had fully adequate land for subsistence farming.

\section{Current Research Projects of the Institute}

Cameroons Research: Dr. Phyllis Kaberry, who, on behalf of the Institute and at the request of the Nigerian Government, has been making a study of the position of women among the peoples of the Cameroons under British Mandate, has completed her field researches and returned to England in April. She will present a short report of the main results of her investigations and will follow it by a major study of the Nsau and other peoples of Bamenda. Ethnographic Survey of Africa: Preliminary surveys have been carried out for the Ibo, Ibibio, Yoruba, and other peoples in the Southern Provinces of Nigeria as well as for some of the pagan peoples of the Northern Provinces; summarized reports have been circulated or are in preparation. Data are being assembled for the Gold Coast, and a survey of the Akan 